\title{
THE INFLUENCE OF THE MINERAL FILLER ON THE ADHESION BETWEEN AGGREGATES AND BITUMEN
}

\author{
A.R. Pasandín ${ }^{a}{ }^{*}$ and I. Pérez ${ }^{a}$ \\ ${ }^{a}$ Universidade da Coruña, E. T. S. I. Caminos, Canales y Puertos, Campus de Elviña s/n, 15071. A \\ Coruña, Spain \\ * Corresponding author. Tel.: +34-981167000. Fax: +34-981167170 \\ E-mail addresses: arodriguezpa@udc.es (A.R. Pasandín),iperez@udc.es (I.Pérez)
}

\begin{abstract}
The loss of adhesion is a major mechanism of physical distress in hot-mix asphalt (HMA) because it could reduce the durability of HMA. In this study, active and passive adhesion between the aggregates and the bitumen that are part of HMA were analysed. As part of the analysis, the Boiling Water Test and measurements of the mixing times were conducted. Four aggregates (hornfels, feldspatic schist, gabbro and dolomitic calcite) and five fillers (from natural aggregate, from natural aggregate $+1 \%$ hydrated lime, commercial limestone, grey Portland cement and fly ash) were used to generalise the conclusions. The experimental results indicated that the use of filler, particularly the grey Portland cement, improves the passive adhesion. The results also indicated that the use of natural filler results in the worst active adhesion. The statistical analysis confirmed the observed results and indicated that active and passive adhesion are not related.
\end{abstract}

Keywords: aggregate-bitumen adhesion, cohesion, water resistance, durability.

\section{Introduction}

Hot-mix asphalt (HMA) is a construction and building material that is widely used at a global level [1] for flexible pavements in the road industry. Nevertheless, this material presents a serious drawback: HMA may fail due to poor water resistance. Indeed, water is the major cause of failure in HMA [2] because the presence of water could lead to a loss in the structural strength and durability of the HMA [3].

HMA is composed of aggregates of various sizes that must be completely coated by the binder, that is, the bitumen. When HMA is in service, water can interact both in the liquid state and as vapour [4] or even in the solid state. Thus, water can damage HMA in several ways, such as the freezing of entrapped water [5], the loss of adhesion between the aggregate-binder interface and a lack of cohesion of the mastic [6]. These two later mechanisms are the two primary driving mechanisms of moisture damage [5]. Among them, the loss of adhesion is a major mechanism of physical distress in bituminous mixtures [7]; however, 
this damage mechanism usually does not work alone and typically coexists with the lack of cohesion [8, 9].

Note that in the road pavement industry, two types of adhesion can be distinguished: active and passive adhesion [10]. Active adhesion is the ability of the binder to completely coat the aggregate during the mixing operation in the HMA manufacture plant, while passive adhesion is the ability of the binder to remain on the aggregate surface without risk of displacement due to the action of water and traffic during the service life of the asphalt [11].

On the one hand, a poor aggregate coating by the binder, that is, an inadequate active adhesion during the HMA manufacturing process, could lead to the creation of pathways through which water could penetrate. On the other hand, the loss of passive adhesion as a consequence of the action of water and traffic during the service life of the HMA could accelerate the creation of several pavement distresses, such as ravelling, cracking, bleeding, potholes, or premature rutting (figure 1) and could also increase its extent and severity $[2-3,8,12-13]$. These pavement distresses result in a loss of comfort and road safety, as well as a reduction in the strength and durability of the pavement [14].

A great variety of products are available to improve the moisture damage resistance of the mixtures. These products include the use of mineral fillers (mineral powders with physical size passing the 0.063 mm sieve) which have a decisive influence on the adhesion between the aggregate and the binder for two reasons [15]. The first reason is that the mineral filler fill the voids in the bituminous mixtures, thereby preventing water entry. The second reason is that several mineral fillers exhibit a better chemical affinity with the bitumen than with the aggregate. In this regard, some authors indicate that the use of Portland cement as filler leads to an improvement in the water resistance of the mixture $[8,16]$. Other authors stated that using fly ash as mineral filler also improves the water resistance of HMA $[5,16]$. Nevertheless, hydrated lime is the most used anti-stripping agent, generally in percentages of $1 \%$ to $2 \%$ by dry weight of the aggregate $[3,5,16-17]$.

In this regard, the aim of this study is to analyse the influence of mineral filler on both active and passive adhesion between the aggregates and the bitumen, with the ultimate objective of improving the water sensitivity and therefore, the performance and the durability of HMA against the action of water; thereby improving road service quality and traffic safety and reducing the costs of operating and maintaining the 
pavement of highways In addition, an analysis is performed regarding whether there is any relationship between the active and passive adhesions. To compare and generalise the findings, this investigation was conducted with aggregates of four different mineralogical compositions. To perform the analysis of the aggregates and bitumen passive adhesion, the Texas Boiling Water Test was selected, due to its short measurement time and simplicity [18]. To perform the analysis of the aggregate and bitumen active adhesion, the mixing times were measured.

\section{Materials}

\subsection{Aggregates}

Four types of aggregates typically used in Spain in road construction were selected to perform this work: hornfels, feldspatic schist, gabbro and dolomitic calcite. Because the analysis of the adhesion between the aggregate and the binder requires knowledge of the siliceous or limestone nature of the aggregates, an analysis of the chemical composition and crystalline phases of the asphalt were conducted.

X-ray fluorescence (XRF) spectroscopy (Bruker S4 Pioneer Fluorescence Spectrometer) was used to determine the bulk composition in the weight of the aggregates. As presented in table 1, the composition of hornfels, feldspatic schist and gabbro is mainly siliceous. Consequently, these aggregates have a high potential to exhibit poor moisture damage performance. On the contrary, dolomitic calcite aggregates are a mainly limestone aggregate, and thus, adequate water resistance is expected.

The crystallography was evaluated using the X-ray diffraction (XRD) method (Siemens D5000 X-ray diffractometer). Figure 2 shows the results of the X-ray diffraction test. Note that hornfels and feldspatic schist mainly present quartz in their mineralogical composition. Because quartz usually has a poor adhesion with the binder [19], it is expected that the adhesion with the bitumen is not adequate. The gabbro mainly exhibit chlorite-serpentine in its mineralogical composition. Chlorites are present in nonpolar active sites, which are generally found on hydrophobic surfaces [20]. Nevertheless, taking into account that quartz also appears in the mineralogical composition of the gabbro and that non-polar active sites appear to a lesser degree in the chlorites than in other minerals [21], it is not expected to exhibit good adhesion with the binder. Cristallography results confirm the XRF results in the case of dolomitic calcite. This aggregate is mainly composed of dolomite, thus a good adhesion with the bitumen is expected [19]. 


\subsection{Binder}

A penetration grade bitumen B50/70 was used as the binder. The bitumen came from Venezuela and is typically used in the hot-mix asphalt industry in Spain. The bitumen penetration grade was obtained following the Spanish standard NLT-124/84 [22]. In this test, the amount of penetration produced in a sample of bitumen at $25^{\circ} \mathrm{C}$ by a calibrated needle, which is charged with $100 \mathrm{~g}$ and is allowed to act for 5 seconds, is measured. As expected, the penetration grade obtained for B50/70 (5.2 mm) was between 5.0 $\mathrm{mm}$ and $7.0 \mathrm{~mm}$.

\subsection{Filler}

In this study, in addition to filler from natural aggregate, four mineral fillers were chosen among the most used to improve the adhesion between the aggregates and the bitumen. These four fillers were filler from natural aggregate $+1 \%$ hydrated lime CL-90 S (minimum content of $\mathrm{CaO}+\mathrm{MgO} 90 \%$ ); commercial limestone $\left(\mathrm{SiO}_{2}<0.08 \%\right.$ and $\left.\mathrm{CaO}>63.77 \%\right)$; grey Portland cement CEM II/B-M (V-L) $32.5 \mathrm{~N}$; and fly ash $\left(\mathrm{SiO}_{2}\right.$ content between $33.1 \%$ and $63.5 \%$ and $\mathrm{CaO}$ content between $1.85 \%$ and $\left.11.5 \%\right)$.

Since the grain size of the filler can influence the aggregate-bitumen adhesion, figure 3 includes the grain size distribution of the fillers used in the present investigation, obtained by means of laser diffraction (light scattering) using a Saturn Digisizer II equipment. As can be seen, the commercial fillers (fly ash, commercial limestone, Portland cement and hydrated lime) have finer size distribution than the filler from natural aggregates (hornfels, feldspatic schist, gabbro and dolomitic calcite).

\section{Experimental studies}

\subsection{Passive adhesion}

Passive adhesion analysis was conducted following the standard ASTM "D 3625 - 96 Standard Practice for Effect of Water on Bituminous-Coated Aggregate Using Boiling Water" [26]. This standard describes a method that is easy to perform, efficient and sufficiently fast for the determination of the water sensitivity of the aggregates coated with bitumen. As shown in figure 4, a sample of approximately $250 \mathrm{~g}$ of loose asphalt mixture made with aggregates of fraction $8 / 11.2 \mathrm{~mm}$ is cooled to a temperature between $85^{\circ} \mathrm{C}$ and the boiling point of water. After reaching the target temperature, the sample is then introduced into a container with boiling distilled water for 10 minutes. After this time, the bitumen that remains at the water surface is skimmed off, and then the sample is cooled to room temperature. Next, after decanting the water, the sample is placed onto a white paper towel, and then the observations of the 
degree of bitumen coating are performed. In this test, the minimum coating requirements, considering that the binder exhibits good adhesion, are 85-90\% [6].

Four control samples (with natural filler) and 16 samples, including all possible combinations of aggregate and fillers, were analysed. In all cases, the loose mixture was made with $4 \%$ mineral filler by the total weight of aggregate and 3\% bitumen by the total weight of the mixture. In addition, an analysis of the bitumen coatings obtained in a loose mixture without filler was conducted to determine whether the use of filler improves the results.

\subsection{Active adhesion}

To obtain a measure of the ease of achieving the aggregate coating by the binder, the mixing times of the different combinations of aggregates and mineral fillers were measured. Both the aggregates and the bitumen were heated at the temperature of $170{ }^{\circ} \mathrm{C}$. This test determined the time in seconds elapsing between the moment in which the bitumen is added to the mixing bowl and the moment when $100 \%$ bitumen coating is achieved.

\subsection{Data statistical analysis}

First, a two-way analysis of variance (ANOVA) was conducted to analyse the statistical significance of the mineral filler and the type of aggregate in the passive adhesion between aggregate and binder. The bitumen coverage was the dependent variable in each case. The two factors were the type of aggregate (hornfels, feldspatic schist, gabbro and dolomitic calcite) and the type of mineral filler (natural, natural + $1 \%$ hydrated lime, commercial lime, CEM II/ B-M (V-L) $32.5 \mathrm{~N}$ and fly ash). Both factors were qualitative variables, while the bitumen coverage is a quantitative variable.

Additionally, another two-way ANOVA was performed to determine the effects of the type of mineral filler and the type of aggregate on the mixing time, that is, in the active adhesion.

In this case, the dependent quantitative variable is the mixing time to achieve $100 \%$ bitumen coverage. The two factors are the same as the factors used in the first ANOVA.

In addition, one one-way ANOVA was performed with the aim of analysing if there is a statistical significance between the bitumen coverage obtained in the Boiling Water Test and the mixing time, that is, to analyse the relationship between passive adhesion and active adhesion.

PASW Statistics 18 was used in all cases to perform the statistical analyses. 


\section{Results and discussion}

\subsection{Passive adhesion}

Figure 5 shows the bitumen coverage obtained in the Boiling Water Test versus the type of mineral filler and the type of aggregate. As expected, figure 5 clearly shows that using mineral filler notably improves the passive adhesion between the aggregates and the binder. Nevertheless, there are exceptions, probably due to the dispersion of this test or the heterogeneous composition of the aggregates, particularly the feldspatic schist. In this regard, the loose mixture made with feldspatic schist and commercial lime and the loose mixture made with feldspatic schist and fly ash produced worse results than that obtained with the loose mixture made with feldspatic schist without filler. Figure 5 also shows that using Portland cement CEM II/B-M (V-1) $32.5 \mathrm{~N}$ as filler clearly results in better bitumen coverage for most aggregates. Again, the loose mixture made with feldspatic schist and Portland cement is an exception. However, in this case, using Portland cement with feldspatic schist results in a bitumen coverage that is only $5 \%$ lower than the maximum bitumen coverage obtained with the feldspatic schist, that is, the results obtained using natural filler or natural filler $+1 \%$ hydrated lime.

Curiously, from the results of figure 5, the limestone aggregates cannot be concluded to yield better results than those of siliceous type. This result indicates that, in addition to the mineral composition, there are many other factors that affect the adhesion, such as texture [1] or porosity, which may be, in some cases, dominant.

\subsection{Active adhesion}

Figure 6 shows the active adhesion results for all of the aggregates and mineral fillers, in terms of the mixing time. As observed, in general, Portland cement, fly ash and commercial limestone are the fillers that achieve lower mixing times. That is, it is easier to achieve $100 \%$ bitumen coverage during the manual mixing process using these fillers. On the contrary, using the filler from the aggregate or the filler from the aggregate $+1 \%$ lime exhibits the worst results. That is, natural fillers seem to exhibit the worst active adhesion, probably due to the greater grain size.

\subsection{Relationship between passive and active adhesion}

It is interesting to analyse if there are any relationships between the passive and the active adhesion. With this aim, figure 7 represents the mixing time versus the bitumen coverage for the four aggregates used in this study. From figure 7, it can be clearly concluded that there is no relationship between the active and passive adhesions. For example, as observed in figure 6, using fly ash as mineral filler yields very low 
mixing times for all of the aggregates; however, the use of mineral filler results in the worst bitumen coverage (figure 5). In contrast, when using Portland cement as filler, very low mixing times (figure 6) are also obtained, but it is the mineral filler that achieves the best bitumen coverage results (figure 5). That is, in view of the results, it can be stated that there is no relationship between the active adhesion and the passive adhesion.

\subsection{Statistical data analysis}

To analyse the statistical significance of the above-described results, two two-way ANOVA tests were performed. As stated in Section 3.3, the first ANOVA was conducted to analyse the statistical influence of the type of filler and the type of aggregate in the passive adhesion. The results from the first ANOVA indicate that the type of mineral filler is statistically significant for the passive adhesion $(\mathrm{p}=0.003<$ $0.05)$. On the contrary, the type of aggregate was not statistically significant $(p=0.191>0.05)$. Thus, statistical analysis confirms the results described in Section 4.1.

The second ANOVA was conducted to analyse the statistical influence of the type of filler and the type of aggregate in the active adhesion. The results from the second ANOVA indicate that both factors, the type of aggregate $(\mathrm{p}=0.032<0.05)$ and the type of mineral filler $(\mathrm{p}=0.000<0.05)$, have statistical significance on the active adhesion. The statistical analysis confirms the results indicated in Section 4.2 related to the type of mineral filler. However, in figure 6, the type of aggregate was not found to exert an influence on the active adhesion. To clarify this observation, a Tukey post-hoc analysis was performed. The results indicated that statistically significant differences only exist between the mixing times obtained with dolomitic calcite and feldspatic schist $(\mathrm{p}=0.067<0.05)$ and the mixing times obtained with dolomitic calcite and gabbro $(\mathrm{p}=0.033<0.05)$.

The third ANOVA was conducted to analyse the statistical influence of the mixing time on the bitumen coverage. That is, this third ANOVA was performed to analyse the statistical significance between the mixing time and the bitumen coverage. As was expected, no statistical significance exists ( $\mathrm{p}=0.416$ $>0.05)$. This ANOVA confirms the results obtained in Section 4.3.

\section{Conclusions}

In this study, the active and passive adhesion between the aggregates and the bitumen that are part of HMA were analysed. The following conclusions were drawn from this study:

- In general, the use of filler improves the passive adhesion between the aggregates and the bitumen, leading to bituminous mixtures with higher water resistance and thus higher durability. 
- Some of the most used fillers were analysed. Among them, the Portland cement, CEM II/B-M

(V-L) $32.5 \mathrm{~N}$ is the filler that, in general, results in better bitumen coverage, that is, in better passive adhesion. Thus, the use of grey Portland cement as filler could help to improve the durability of the bituminous mixtures.

- The natural filler exhibited worse active adhesion results than the commercial products, which have finer grain size distribution.

- No relationship between the active adhesion and the passive adhesion was found. Thus, the filler must be carefully selected so as not to negatively affect the active or passive adhesion while improving the passive or active adhesion.

These conclusions were obtained from the limited investigation that was conducted. Further investigation is required to corroborate and generalise these conclusions. Particularly, investigating more filler types with different grain size distributions is necessary to analysis the influence of the mineral powder grain size on the active adhesion. In this regard, analysis comparing the dynamic and cinematic viscosity of the bitumen with the viscosity of the mastic (mix of bitumen and filler) could also help to explain the influence of the filler grain size distribution on the rheological properties of the bitumen.

\section{Acknowledgments}

The authors acknowledge the Spanish Ministry of Education and Science for sponsoring this research through Project BIA2010-17751.

The authors also thank Nynas bitumen for supplying the binder required for this study.

\section{References}

[1]. Blackman, Bamber R.K.; Cui, Shuan; Kinloch, Anthony J.; Taylor, Ambrose C. "The development of a novel test method to assess the durability of asphalt road-pavement materials". International Journal of Adhesion \& Adhesives 42 (2013) 1-10. DOI: 10.1016/j.ijadhadh.2012.10.013

[2]. Jo, Myung-Chan. "A Study on the Increase in the Durability of Asphalt Paving Mixtures". Petroleum Science and Technology 28:3 (2010) 225-235. DOI: 10.1080/10916460903226080

[3]. Jahromi, Saeed Ghaffarpour. "Estimation of resistance to moisture destruction in asphalt mixtures". Construction and Building Materials 23 (2009) 2324-2331. DOI: 10.1016/j.conbuildmat.2008.11.007

[4]. Caro, S.; Masad, E.; Bhasin, A.; Little, D.N. "Moisture susceptibility of asphalt mixtures, Part 1: mechanisms". International Journal of Pavement Engineering 9:2 (2008) 81-88.

[5]. Kim, Yong-Rak; Pinto, Ingrid; Park, Seong-Wan. "Experimental evaluation of anti-stripping additives in bituminous mixtures through multiple scale laboratory test results". Construction and Building Materials 29 (2012) 383-393. DOI: 10.1016/j.conbuildmat.2011.10.012

[6]. Kiggundu, B.M.; Roberts, F.L. "Stripping in HMA mixtures: state-of-the-art and critical review of test methods". NCAT Report 88-02, 1988.

[7]. Grönniger, Jens; Wistuba, Michael P., Renken, Peter. Adhesion in Bitumen-Aggregate Systems. Road Materials and Pavement Design 11:4 (2011). DOI: 10.1080/14680629.2010.9690311 
[8]. Behiry, Ahmed Ebrahim Abu El-Maaty. "Laboratory evaluation of resistance to moisture damage in asphalt mixtures". Ain Shams Engineering Journal 4 (2013) 351-363. DOI:

10.1016/j.asej.2012.10.009

[9]. Lyne, Åsa Laurell; Krivosheeva, Olga; Birgisson, Björn "Adhesion between bitumen and aggregate: implementation of spectroscopic ellipsometry characterisation and estimation of Hamaker's constant". Materials and Structures 43 (2013) 1737-1745. DOI: 10.1617/s11527-012$0012-2$

[10]. Bearsley, Sean R.; Haverkamp, Richard G. "Age Hardening Potential of Tall Oil Pitch Modified Bitumen". Road Materials and Pavement Design 8:3 (2007) 467-481. DOI: $10.1080 / 14680629.2007 .9690084$

[11]. Tarrer, A.R.; Wagh, V. "The Effect of the Physical and Chemical Characteristics of the Aggregate on Bonding" SHRP-A/UIR-91-507. Washington DC, 1991.

[12]. Hicks, R. Gary; Santucci, Larry; Aschenbrener, Tim "Introduction and Seminar Objectives". Moisture Sensitivity of Asphalt Pavements: A National Seminar. February 4-6, 2003. San Diego, California. Transportation Research Board.

[13]. Grenfell, James; Naveed, Ahmad; Liu, Yawen; Apeagyei, Alex; Large, David; Airey, Gordon. "Assessing asphalt mixture moisture susceptibility through intrinsic adhesion, bitumen stripping and mechanical damage". Road Materials and Pavement Desing 15:1 (2014) 131-152. DOI: $10.1080 / 14680629.2013 .863162$

[14]. Horgnies, M.; Darque-Ceretti, E.; Fezai, H; Felder, E. "Influence of the interfacial composition on the adhesion between aggregates and bitumen: Investigations by EDX, XPS and peel test. International Journal of Adhesion \& Adhesives 31 (2011) 238-247. DOI: 10.1016/j.jjadhadh.2011.01.005

[15]. Padilla Rodríguez, A. "Análisis de la resistencia a las deformaciones plásticas de mezclas bituminosas densas de la normativa mexicana mediante el ensayo de pista". Tesina, Universitat Politècnica de Catalunya, Spain, 2004.

[16]. Epps, Jon; Berger, Eric; Anagnos, James N. "Treatments". Moisture Sensitivity of Asphalt Pavements: A National Seminar. February 4-6, 2003. San Diego, California. Transportation Research Board.

[17]. Airey, G.D.; Collop, A.C.; Zoorob, S.E.; Elliot, R.C. "The influence of aggregate, filler and bitumen on asphalt mixture moisture damage". Construction and Building Materials 22 (2008) 2015-2024.

[18]. Jo, Myung-Chan; Tarrer, Arthur R.; Jeon, Young W.; Park, Sang Joon;Yoon, Hyon Hee. "Investigation of the effect of aggregate pretreatment with antistripping agents on the asphaltaggregate bond". Petroleum Science and Technology 15:3-4 (1997) 245-271. DOI: $10.1080 / 10916469708949655$

[19]. Bagampadde, U. "On investigation of stripping in bituminous mixtures". Tesis doctoral. Karlstad University, 2004.

[20]. Miller, Clint; Vasconcelos, Kamilla L.; Little, Dallas N.; Bhasin, Amit. "Investigating aspects of aggregate properties that influence asphalt mixture performance". Research Report for DTFH6106-C-00021. Texas A \& M University, College Station and The University of Texas at Austin, Austin. June 2011.

[21]. Johnston, C.T. "Surface Chemistry of soil minerals". Soil Mineralogy in environmental applications. Soil Science Society of America, Madison, WI, 2002.

[22]. MOPT. Normas NLT. I.-Ensayos de Carreteras. CEDEX. Spain, 1992.

[23]. ASTM. D 3625-96. "Standard Practice for Effect of Water on Bituminous-Coated Aggregate Using Boiling Water", 2005. 


\section{Figure 1}

Hot-mix asphalt that has suffered from stripping, as a consequence of a loss of adhesion between the aggregates and the binder due to the action of water.

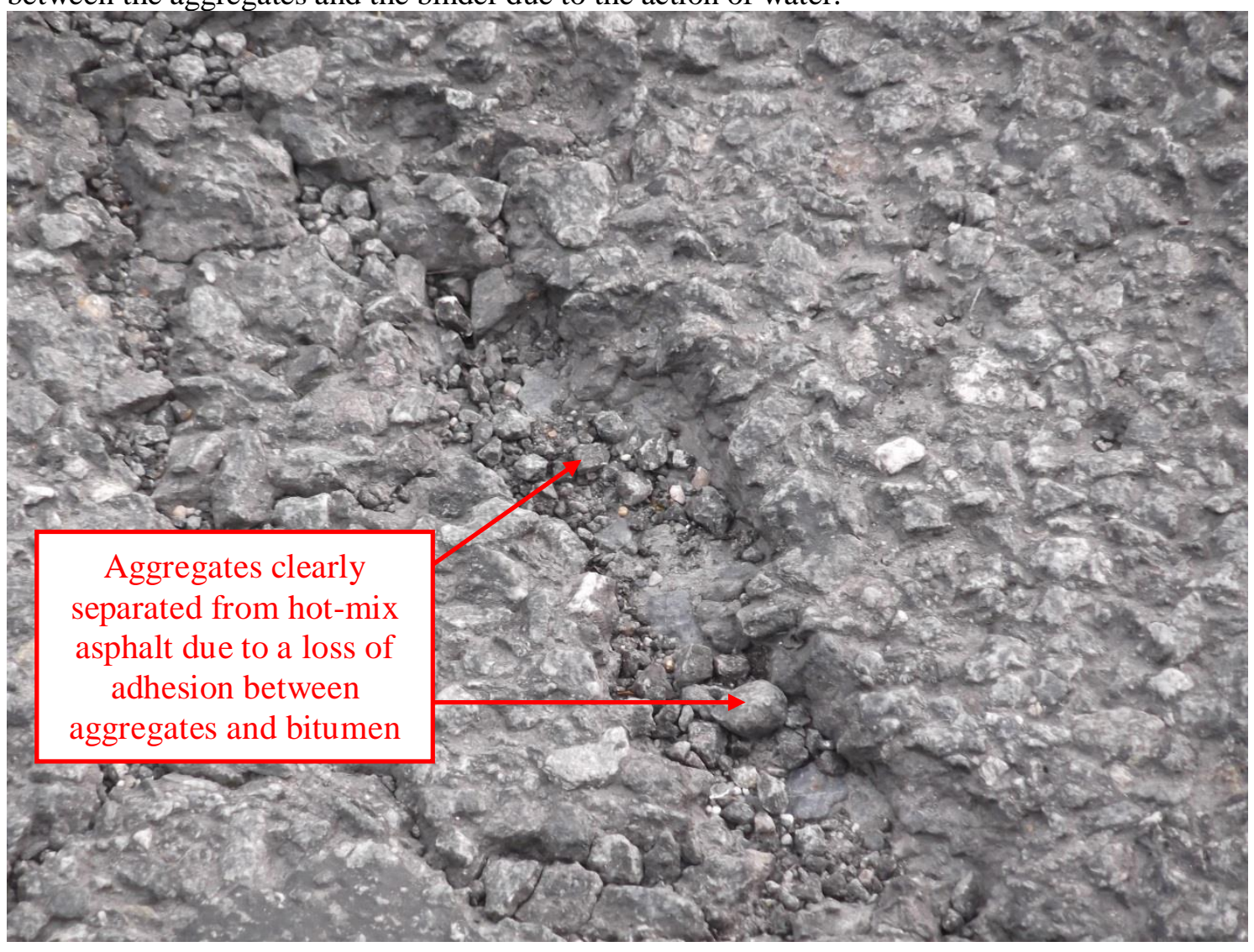


Figure 2

Diffractograms: a) Hornfels, b) feldspatic schist, c) gabbro and d) dolomitic calcite.
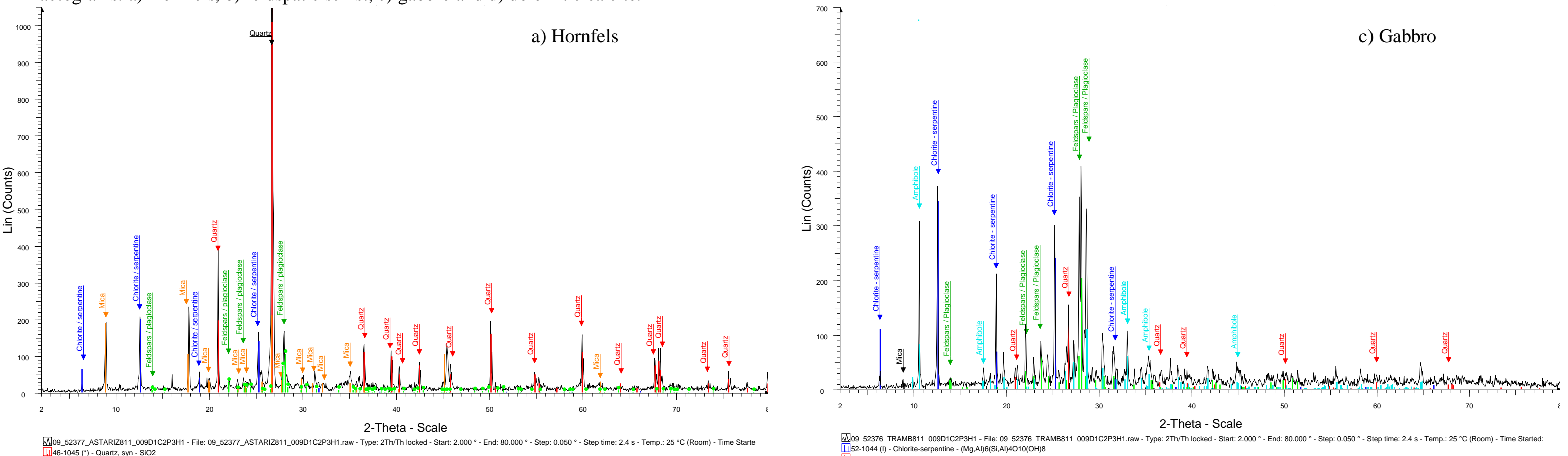

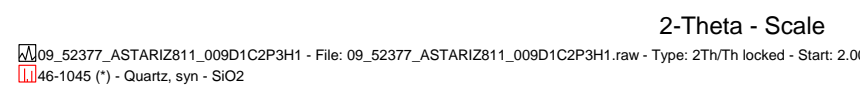

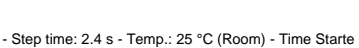

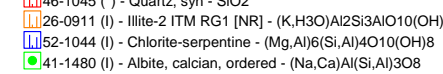
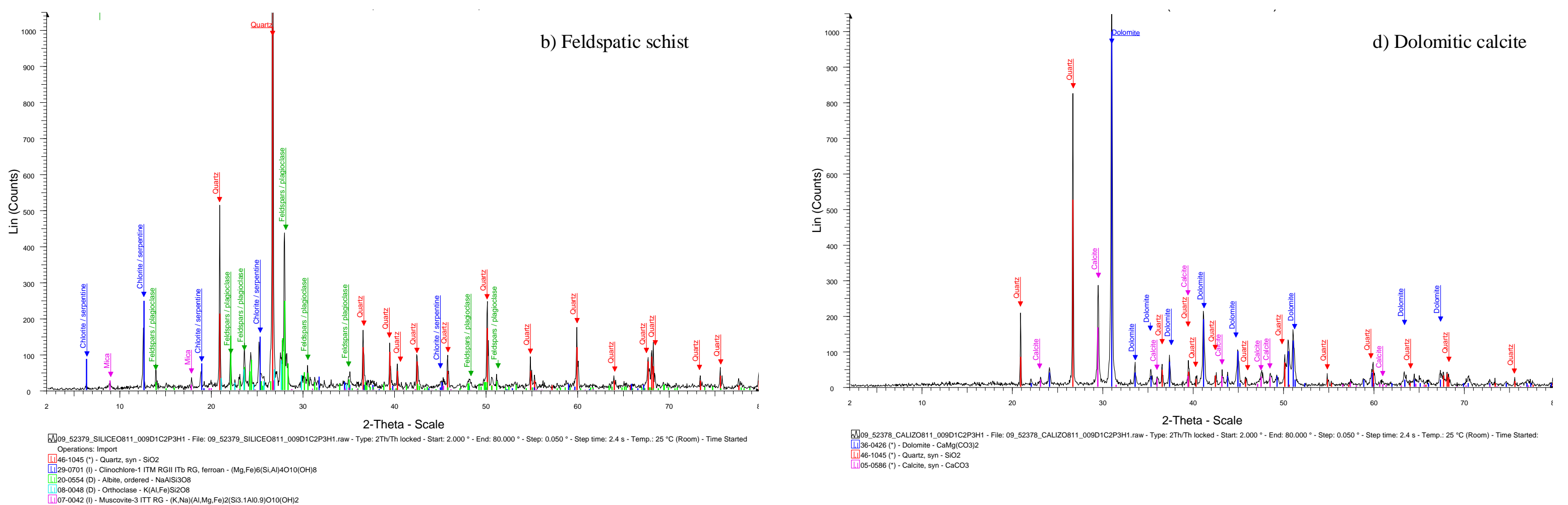
Figure 3

Mineral filler grain size distribution

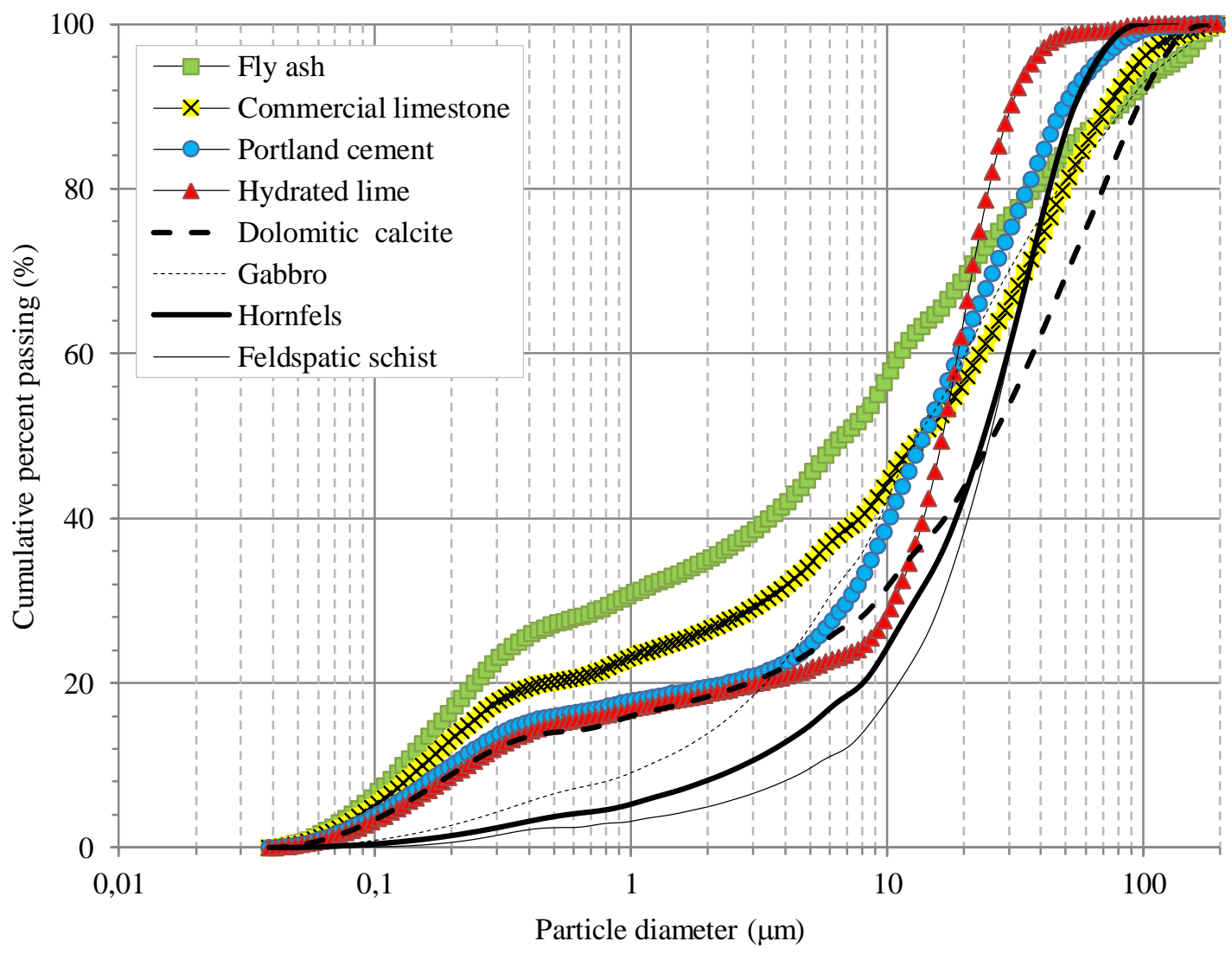


Figure 4

Boiling Water Test procedure

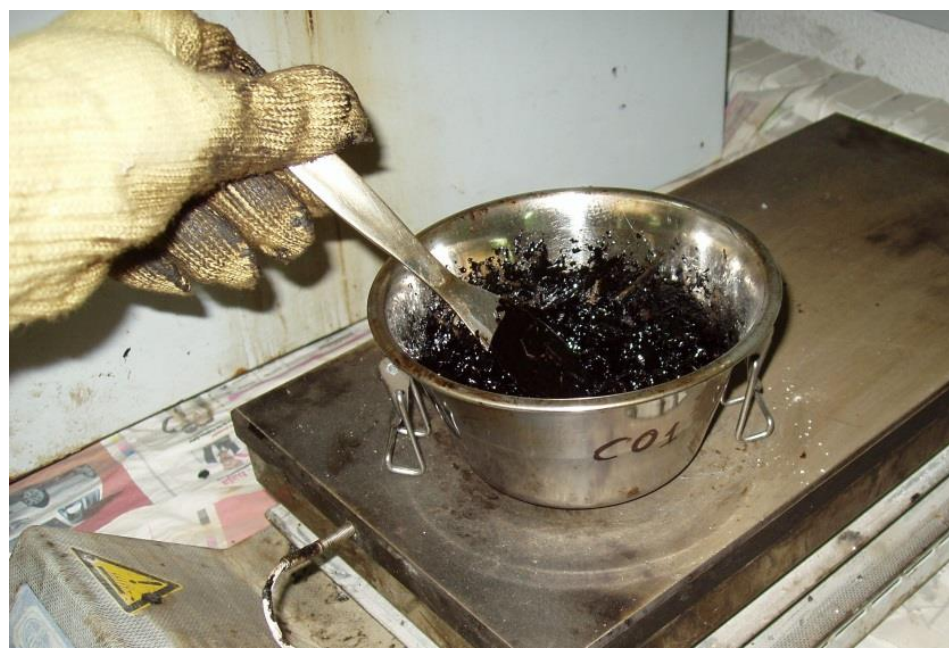

Loose mixture mixing process

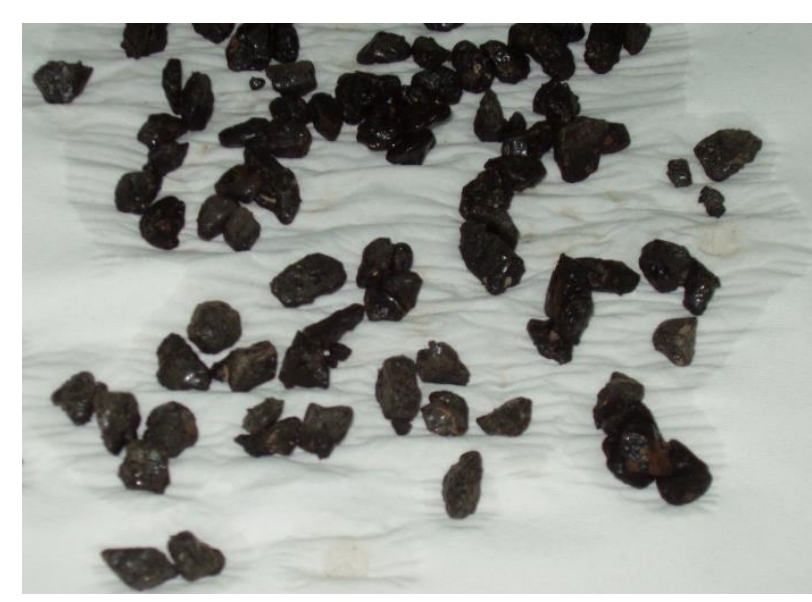

Loose mixture on a white paper towe

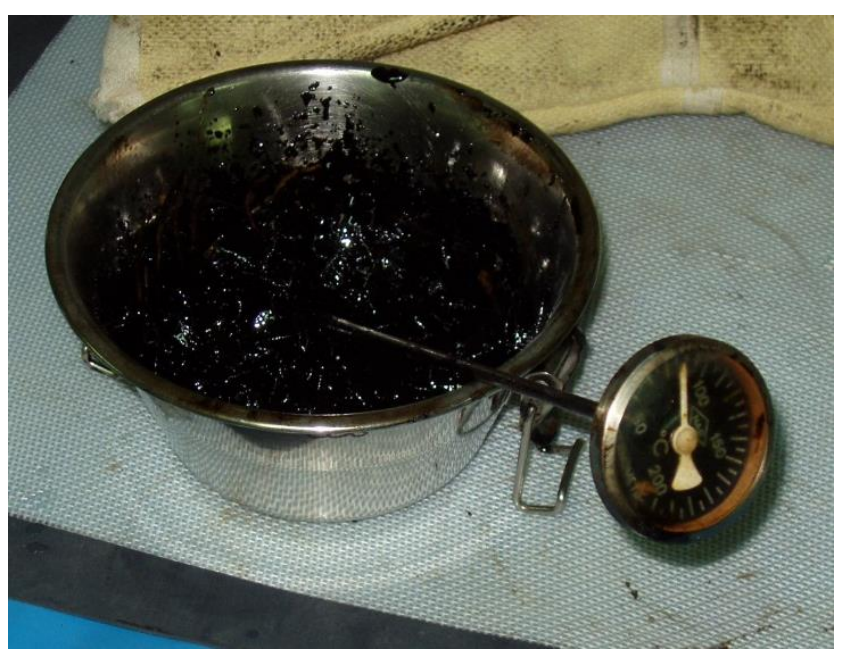

The loose mixture temperature must be between $85^{\circ} \mathrm{C}$ and the boiling temperature of the water

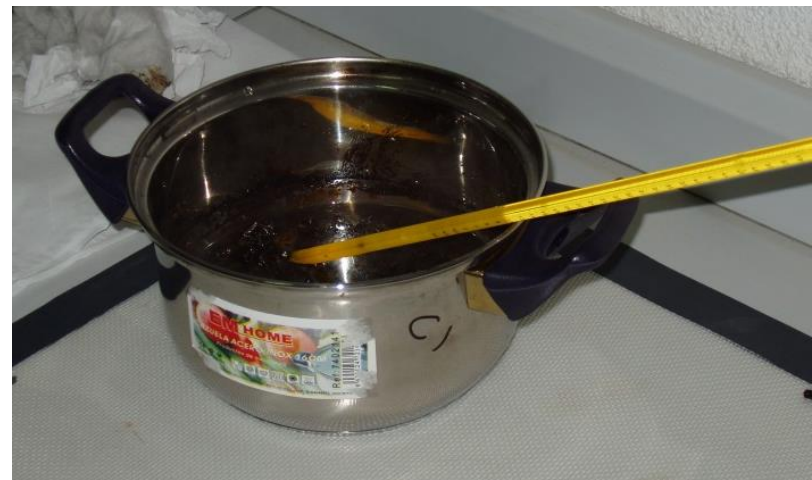

The loose mixture is cooled to room temperature

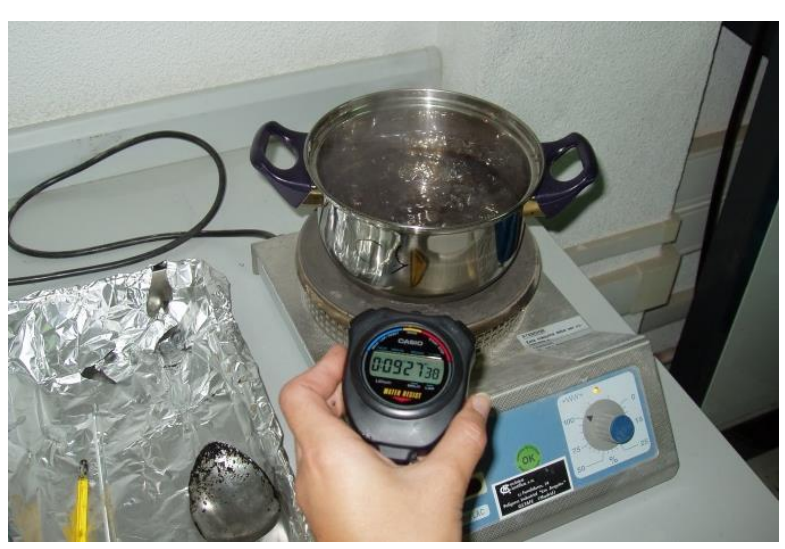

Loose mixture in boiling water for 10 minutes

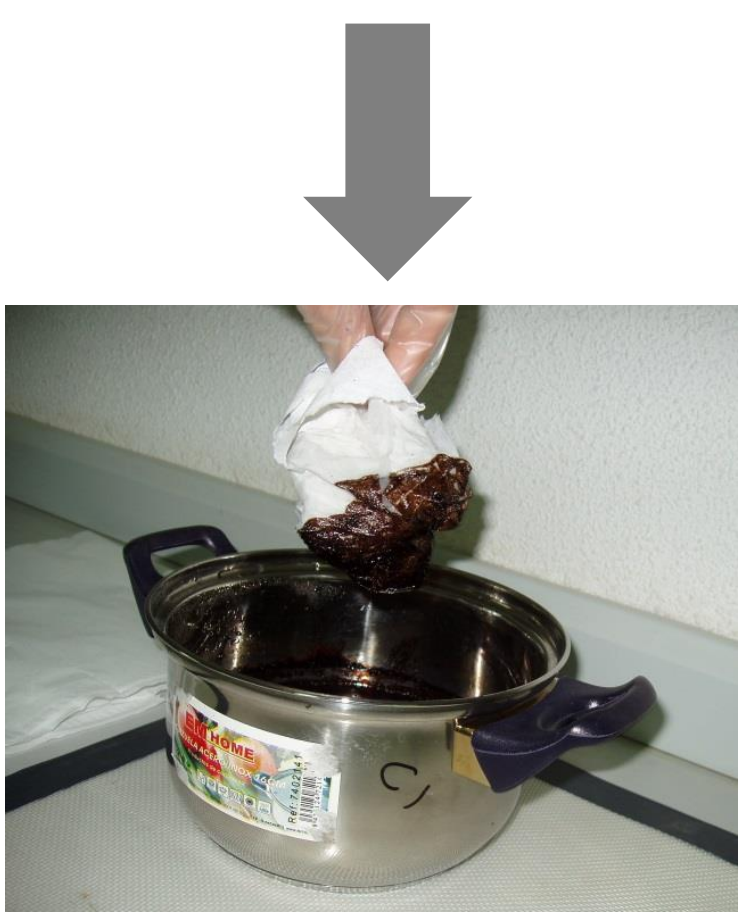

Free bitumen is skimmed of from the water surface 
Figure 5

Passive adhesion results in terms of the bitumen coverage

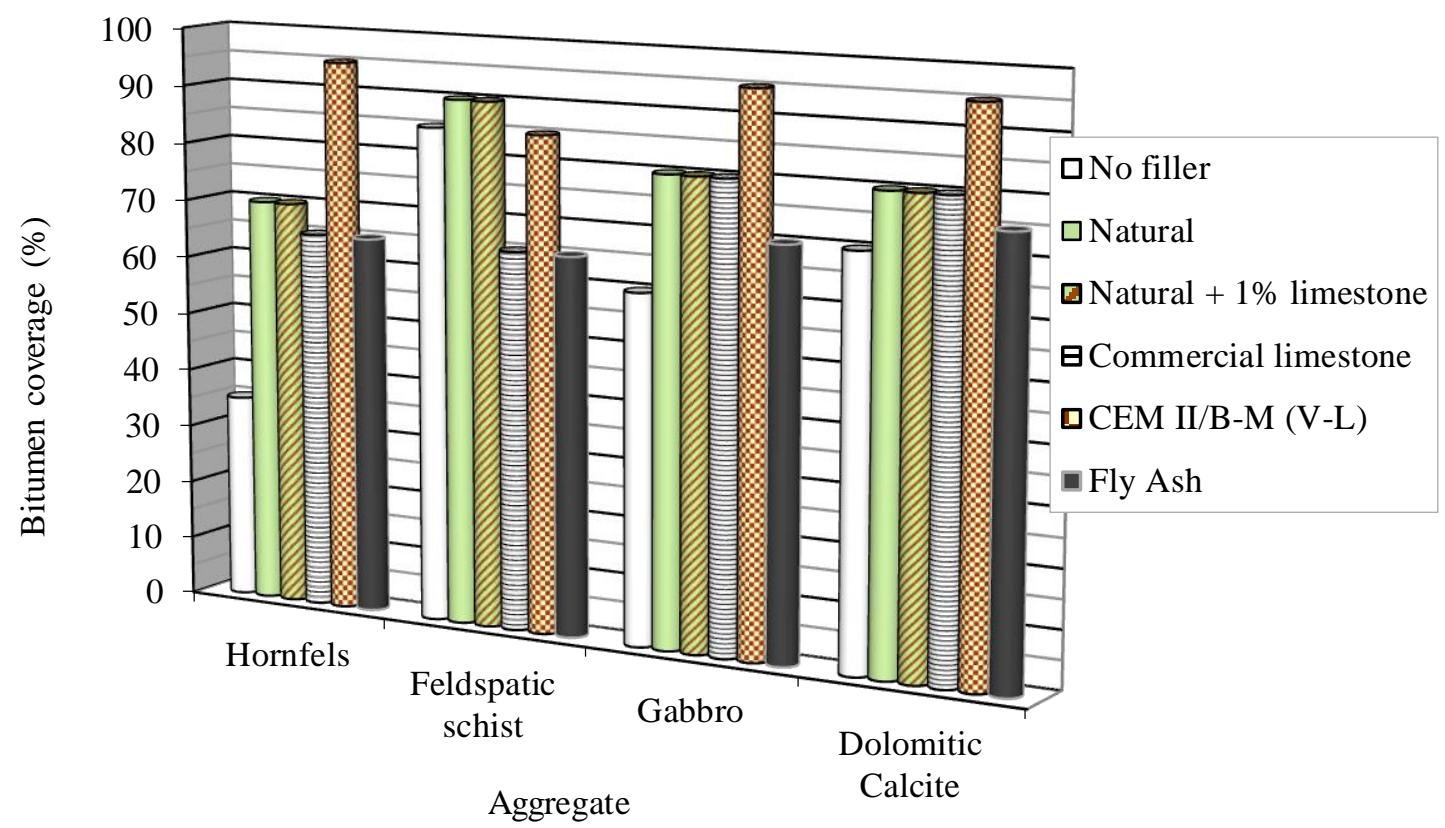


Figure 6

Active adhesion results in terms of the mixing time

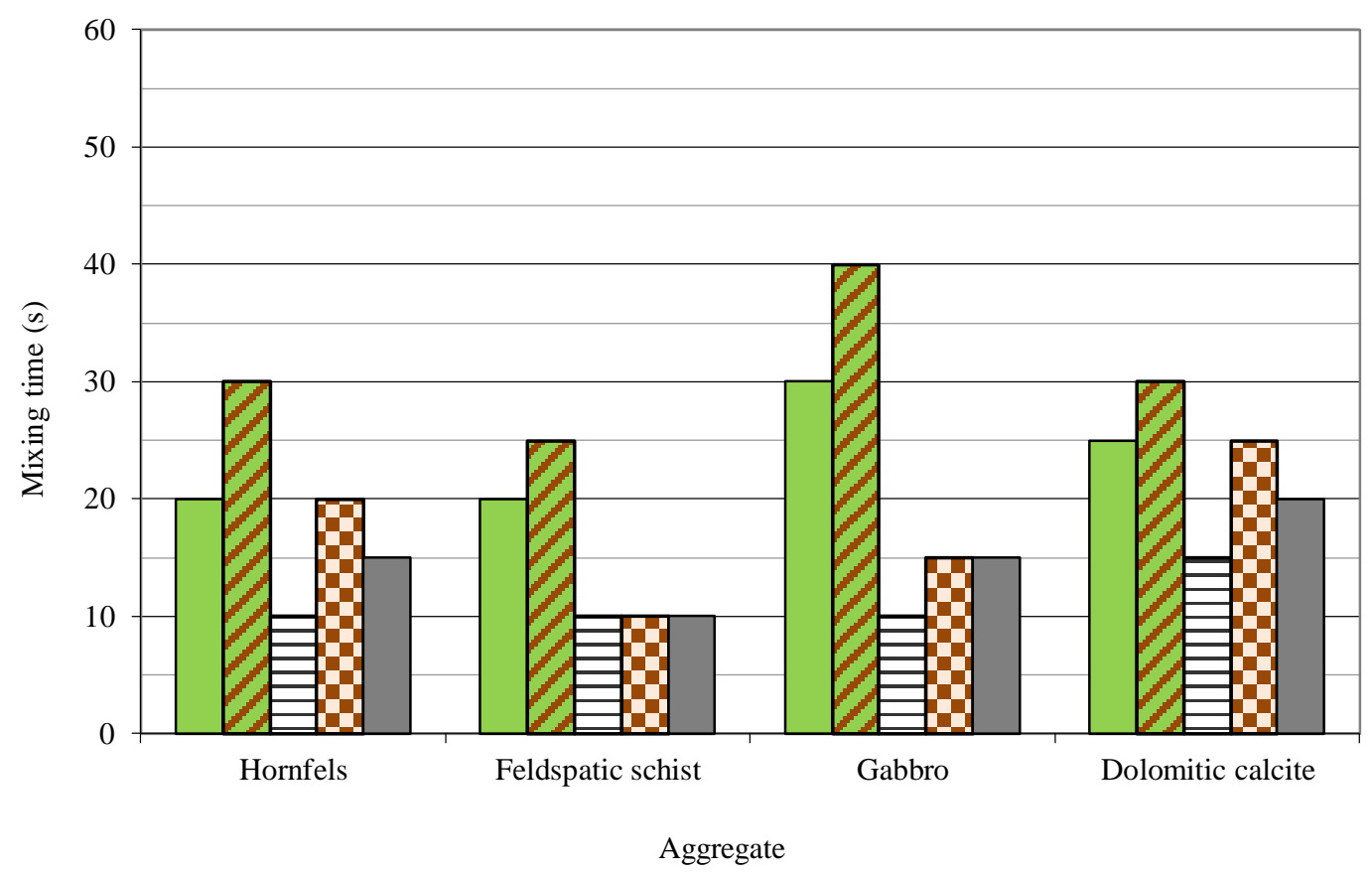


Figure 7

Mixing time versus the bitumen coverage

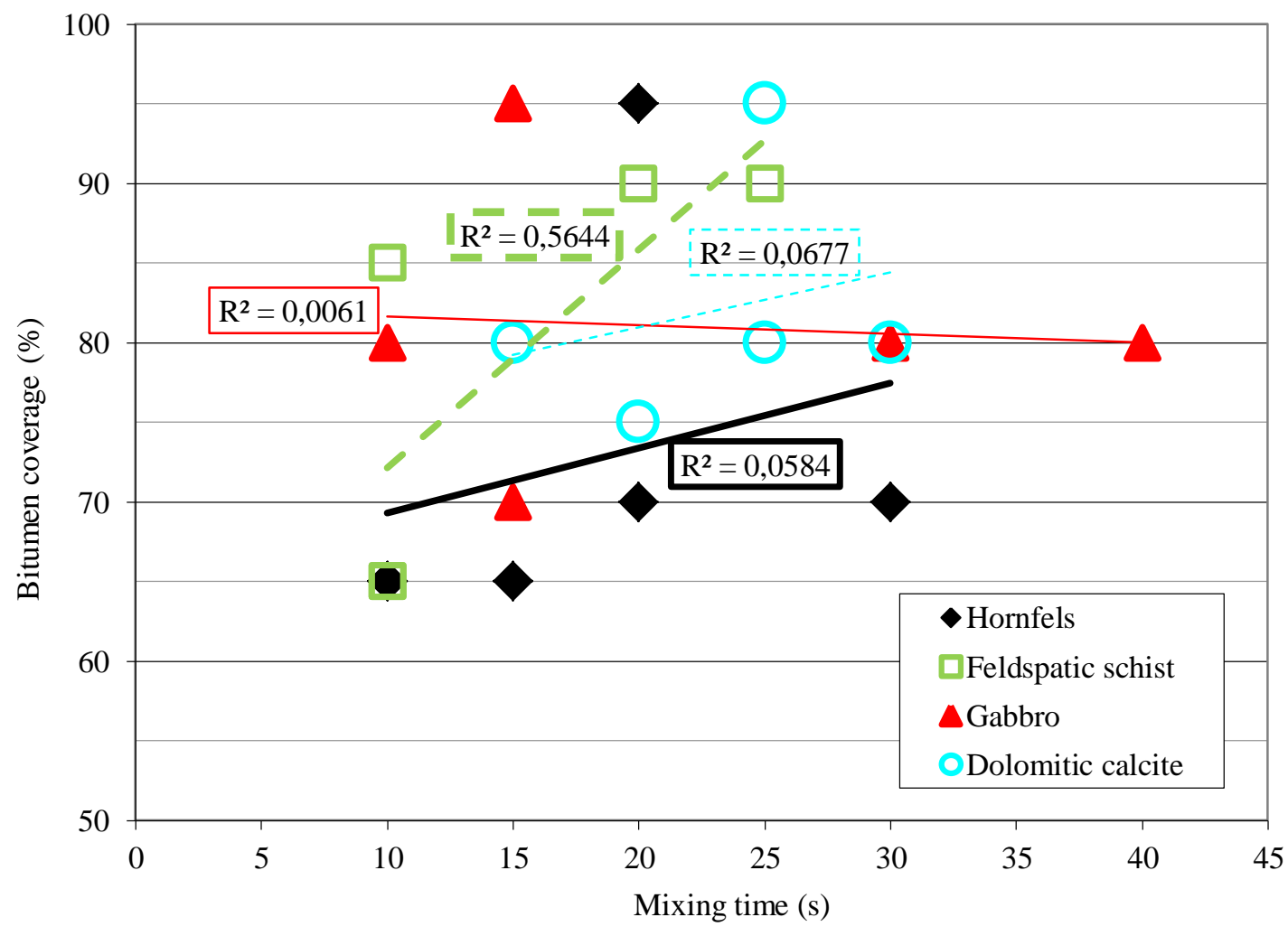


Table 1

Bulk composition in weight of the aggregates according to the $\mathrm{X}$-ray fluorescence results

\begin{tabular}{|c|c|c|c|c|c|c|c|c|c|c|c|c|}
\hline Aggregate & $\begin{array}{l}\mathrm{SiO}_{2} \\
(\%)\end{array}$ & $\begin{array}{l}\mathrm{CaO} \\
(\%)\end{array}$ & $\begin{array}{l}\mathrm{AL}_{2} \mathrm{O}_{3} \\
(\%)\end{array}$ & $\begin{array}{l}\mathrm{K}_{2} \mathrm{O} \\
(\%)\end{array}$ & $\begin{array}{l}\mathrm{CO}_{2} \\
(\%)\end{array}$ & $\begin{array}{l}\mathrm{MgO} \\
(\%)\end{array}$ & $\begin{array}{l}\mathrm{Fe}_{2} \mathrm{O}_{3} \\
(\%)\end{array}$ & $\begin{array}{l}\mathrm{TiO}_{2} \\
(\%)\end{array}$ & $\begin{array}{l}\mathrm{Na}_{2} \mathrm{O} \\
(\%)\end{array}$ & $\begin{array}{l}\mathrm{SO}_{3} \\
(\%)\end{array}$ & $\begin{array}{l}\mathrm{P}_{2} \mathrm{O}_{5} \\
(\%)\end{array}$ & $\begin{array}{l}\mathrm{SrO} \\
(\%)\end{array}$ \\
\hline Hornfels & 62.3 & 0.3 & 19.0 & 4.3 & 2.5 & 1.6 & 7.4 & 0.9 & 1.3 & 0.6 & 0.1 & 0.01 \\
\hline Feldspatic schist & 72.1 & 0.5 & 12.4 & 2.5 & 1.8 & 1.6 & 3.9 & 0.5 & 3.6 & 0.7 & 0.2 & 0.01 \\
\hline Gabbro & 49.2 & 9.6 & 17.5 & 0.6 & 2.4 & 8.0 & 9.0 & 0.7 & 2.4 & 0.1 & 0.1 & 0.03 \\
\hline Dolomitic calcite & 16.1 & 32.3 & 0.8 & 0.2 & 36.7 & 12.6 & 0.9 & - & - & 0.2 & - & 0.03 \\
\hline
\end{tabular}

